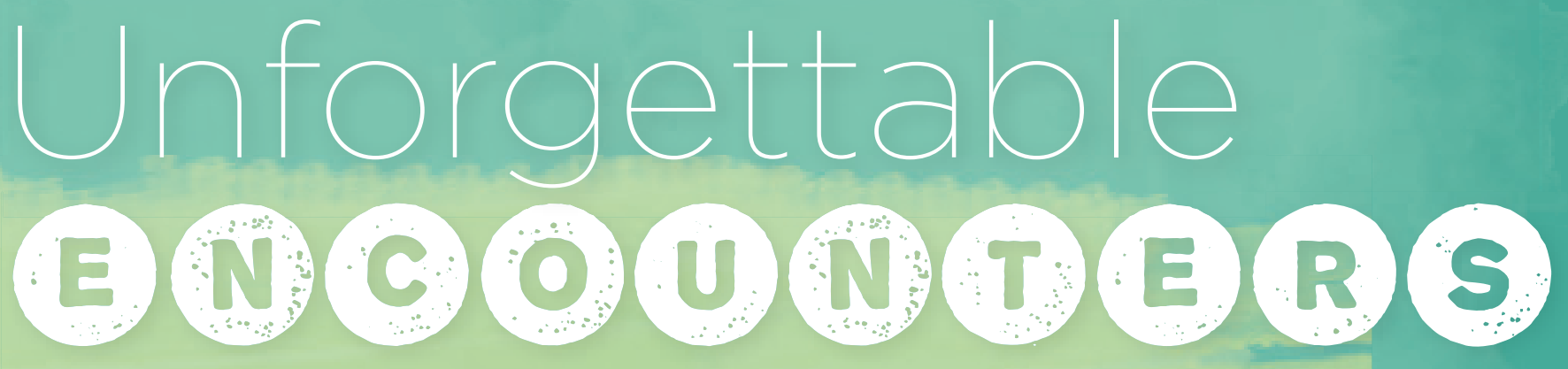

THE SUMMER AFTER HER HUSBAND MOVED OUT, Tiffany Webber met her new neighbors-a noisy couple with odd hours who were building a nest on the ledge outside her Manhattan studio apartment. She called the pigeons the Dudleys and, while grieving the loss of her own marriage, found joy and consolation in their successes: the carefully constructed nest, the hatching of two healthy squabs. "The Dudleys became my therapy birds, comforting me through some of my darkest moments," Webber writes in her recently published essay How New York City Pigeons Comforted Me Through Divorce.

In unexpectedly discovering the healing power of animals, Webber is far from alone. James Bowen describes how a stray orange tabby inspired him to kick a drug addiction in his best-selling book, $A$ Street Cat Named Bob. A cranky horse helped Nancy Shulins overcome the disappointment of unsuccessful fertility treatments, an experience she writes about in Falling for Eli.

Many All Animals readers also have similar stories: about the stray cats and dogs who crossed their paths and became their closest friends. Or the wild animals they glimpsed for just a moment and never forgot. In these edited tributes with accompanying photographs, our readers describe how chance meetings have imparted subtle and profound life lessons.

\title{
Embracing the Good Life
}

I SUPPOSE IT WAS FATE that I ran out of coffee that morning. I went out to get a cup, and on the drive home, something darted into the street. It was a dog — skin and bones with no collar. I raced home and returned with a leash, collar, and treats. It took me about an hour to catch her.

That was two years ago, and Moops is now a happy girl who loves hiking and camping. I love the way she flops over for belly rubs even when I just look at her from across the room.

I took this picture one fall afternoon when we were burning sticks in the fire pit. Moops was lying in the grass and chewing a stick. She looked so vibrant and happy.

- Amy Susney, Hampton, New Jersey

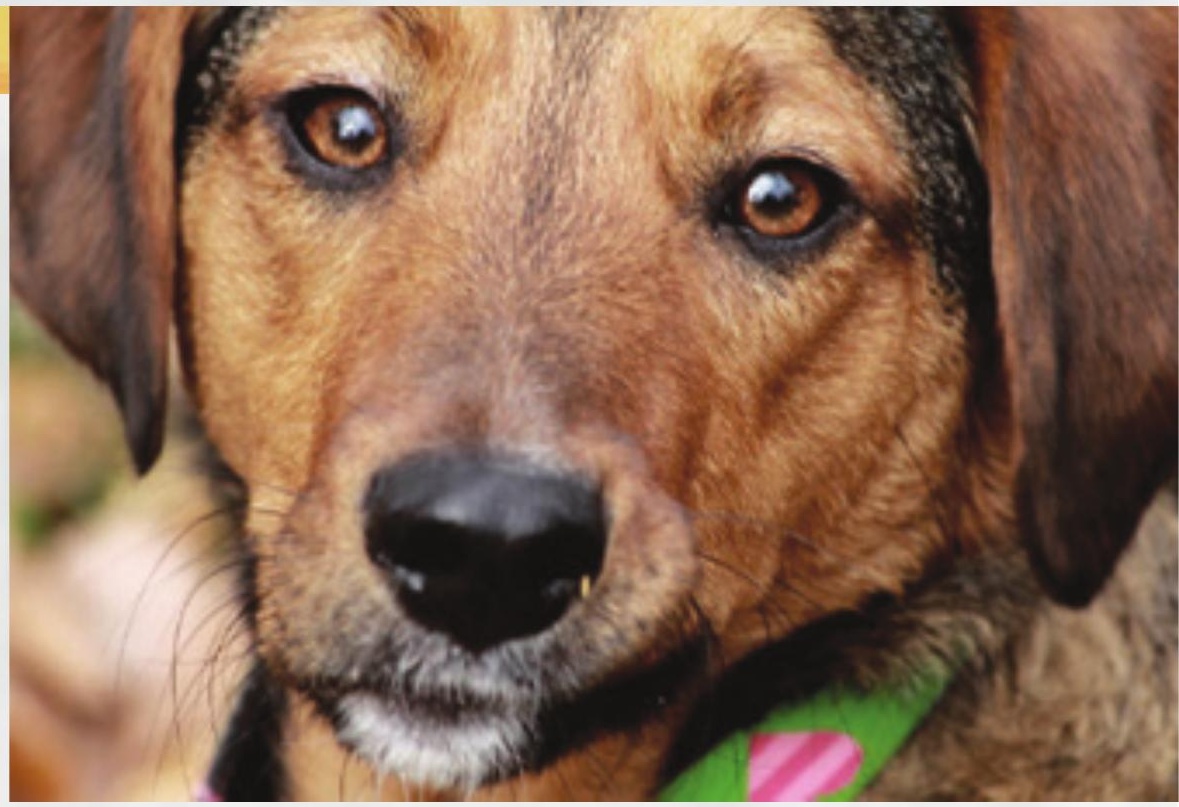




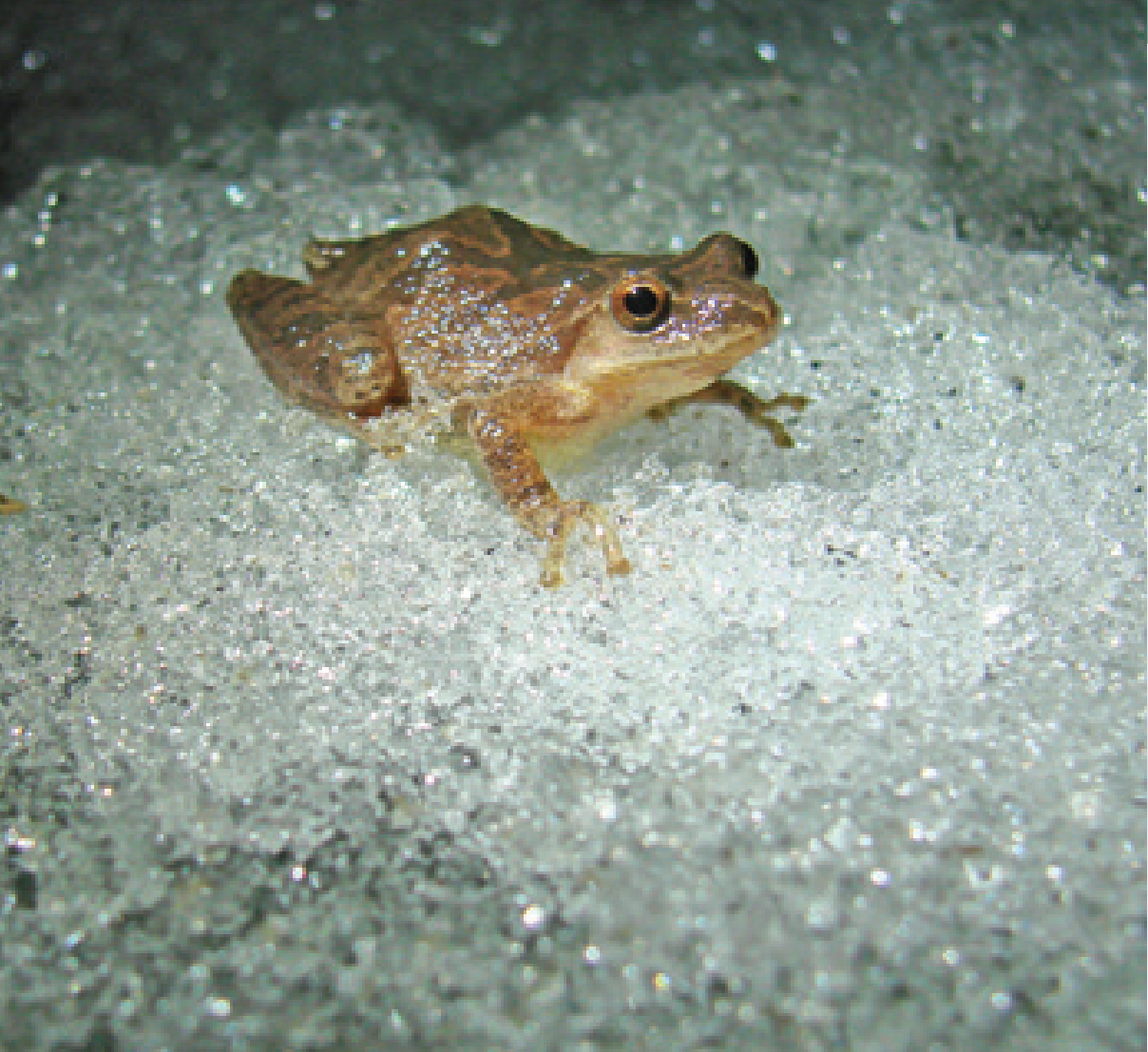

Rising to a Challenge

IT WAS THE FIRST WARM NIGHT of spring, about 50 degrees. My partner and I had scrambled through thornbushes and brambles to document the spotted salamanders at a vernal pool.

At the time, I was working with the Ohio Environmental Council, monitoring these seasonal wetlands that fill in the spring and drain in the summer. They're teeming with life-salamanders, frogs, water scorpions, phantom midges, and fairy shrimp.

As we crept through the dark, I spotted this tiny spring peeper and shined my flashlight on him. I was struck by his determination to venture out in this still frosty landscape to begin his loud peeping call. This little fellow navigated icy waters, predators, and cold temperatures to find a mate and continue the cycle of life.

On that night, I witnessed the universe all wrapped up in a frog. As soon as I snapped my shot, he jumped into the darkness.

- David Celebrezze, Columbus, Ohio

\section{Looking Out for Friends}

I FELL IN LOVE the minute I saw him-a buckskin Clydesdale mix who towered over the other rescued equines at his foster home. Sir had been seized from a cruelty situation, and one of his legs was badly swollen. Even so, his sweet disposition was obvious.

After I brought him to the 5-acre ranch near my home, I put Sir in a pen so the other animals could get to know him. My miniature donkeys kept vigil beside the pen, and when Sir would peer over the railing, they would look up and touch his nose.

Now Sir spends most of his time with his donkey friends. When they start braying, he'll run over and check on them. Sometimes they all take off running in a game of chase. At night, Sir puts himself up in his stall, and the donkeys go in there with him.

This picture captures the life Sir now has: happy, having fun, and knowing that he is loved.

- Lisa Matthews, College Station, Texas

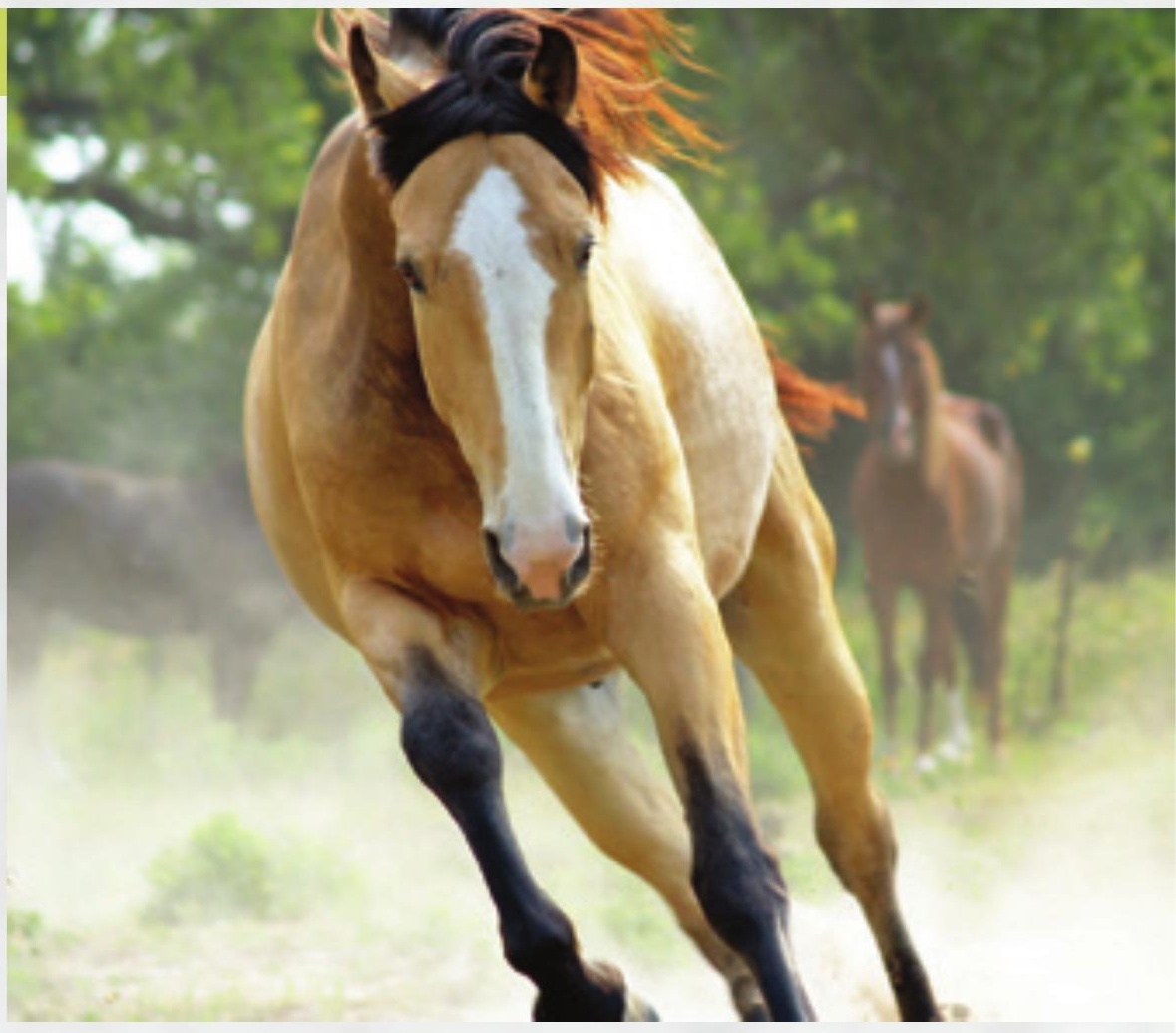




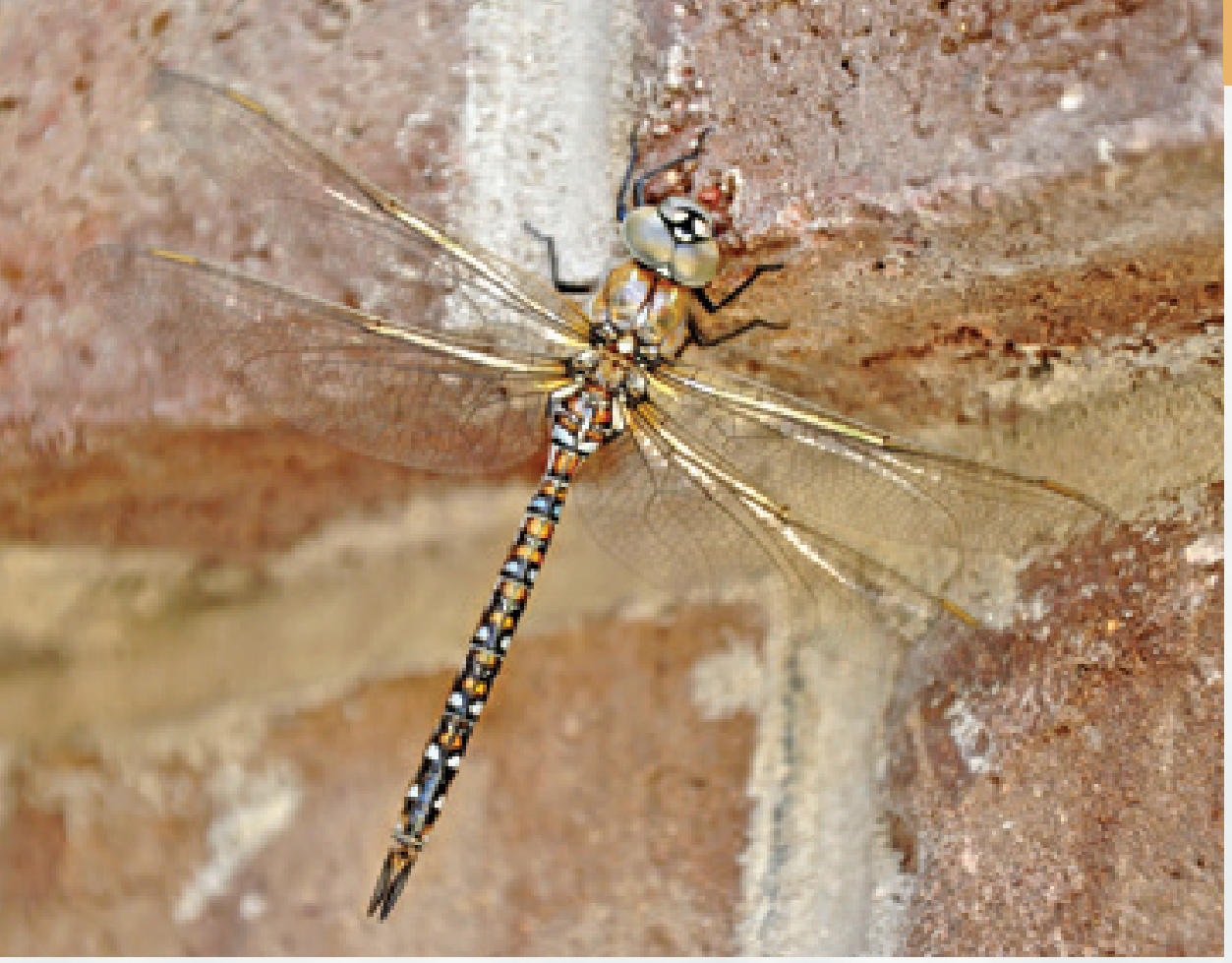

\section{Cherishing Beauty}

AS I SAT ON THE STEPS one spring day watching my kids and their friends play, I noticed this dragonfly perched on the bricks by the door. I called over the kids, who were completely enchanted. We got up close and noted the amazing patterns in his wings and pearliness of his head. The kids stayed perfectly still as I took this picture. Then they decided they wanted to draw dragonflies, so I brought out paper and crayons and our porch became an impromptu art studio. We later learned it was likely a Darner dragonfly, and my son was thrilled to discover that dragonflies eat mosquitoes.

I was thankful for the bit of beauty the experience brought to my day and for the sweet fascination of my children.

- Kristen Allen, Orem, Utah

\section{Spreading Cheer}

THE SUMMER AFTER I graduated high school, my grandparents took me on a three-week trip to Africa. We spent a lot of time riding on a bus because we wanted to see as much as we could. During a bathroom break at a gift shop, I was enjoying the outdoor scenery when this cat walked up to me. Her fur was dirty, but she had the most beautiful eyes. She meowed a few times and then let me and a few others pet her.

She inspires me because even though she was a stray, she still had high spirits. She didn't care that it was muddy outside and hot. This picture will always remind me of how fortunate I am to have everything I have and help me to remember that even when times are rough, I have to make the best of it.

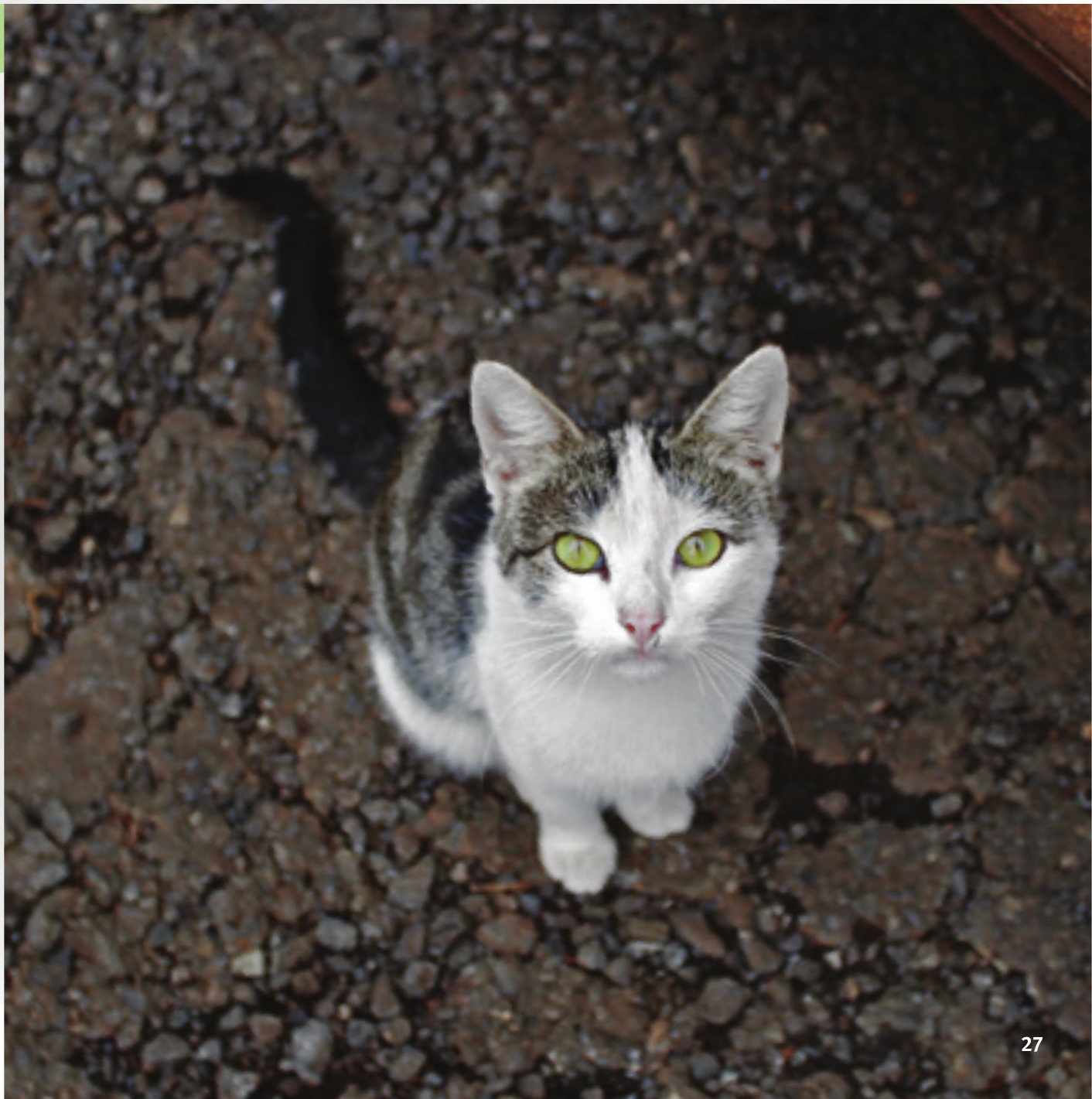




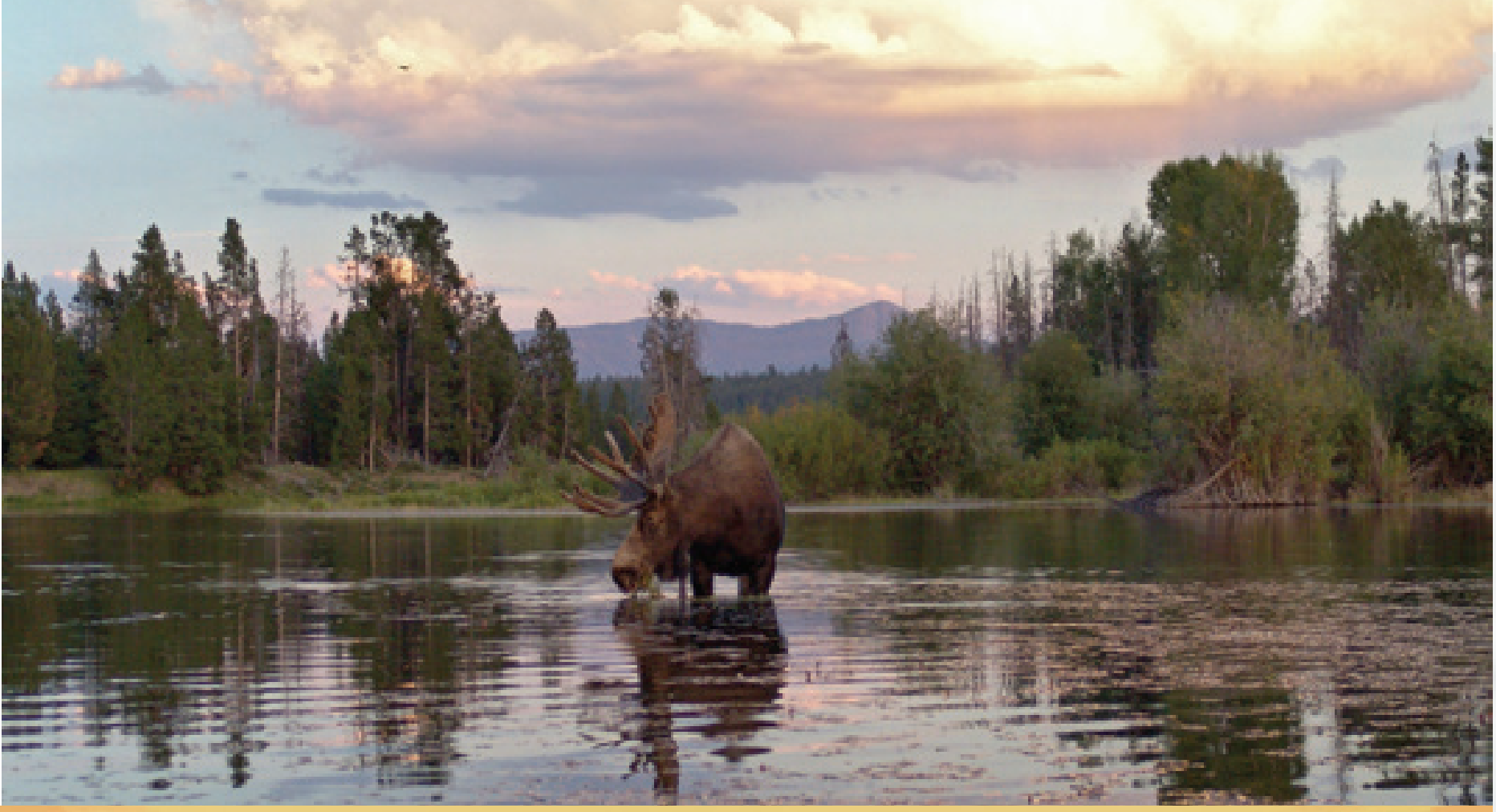

Showing Respect

IN 2007, I SPENT TIME EXPLORING Yellowstone National Park and the Grand Tetons. As I was kayaking on the Snake River one evening, I heard rustling in the willows of a small island nearby. A moose emerged from the willows, walked to the water's edge, and hesitated, looking at me as if to say, "Oh, you're here. I was hoping to go into the water."
As a Christian, I believe God cares profoundly about his creation. And I believe that those of us who love animals have a greater awareness of what the animals we encounter are trying to communicate. I said to the moose: "You want to come out here, so I will let you." Then I paddled backwards to let him drink in peace.

- James Burkett, Arvada, Colorado

\section{Living with Zest}

THE FIRST TIME I saw Pepper was the day I met up with someone selling a bicycle on Craigslist. She was only 2 months old and huddled in the corner, looking scared and not well cared for. I asked to hold her, and when she put her little head on my shoulder, I knew I had to take her home.

She's now 4 years old and so smart and loving. This photo was taken at a local dog beach. People were laughing as Pepper flew over the waves, running back and forth from blanket to ocean and retrieving her ball. We love how curious and brave she can be for such a little dog. She makes us smile every day!

- Klaudia Seidl, Huntington Beach, California

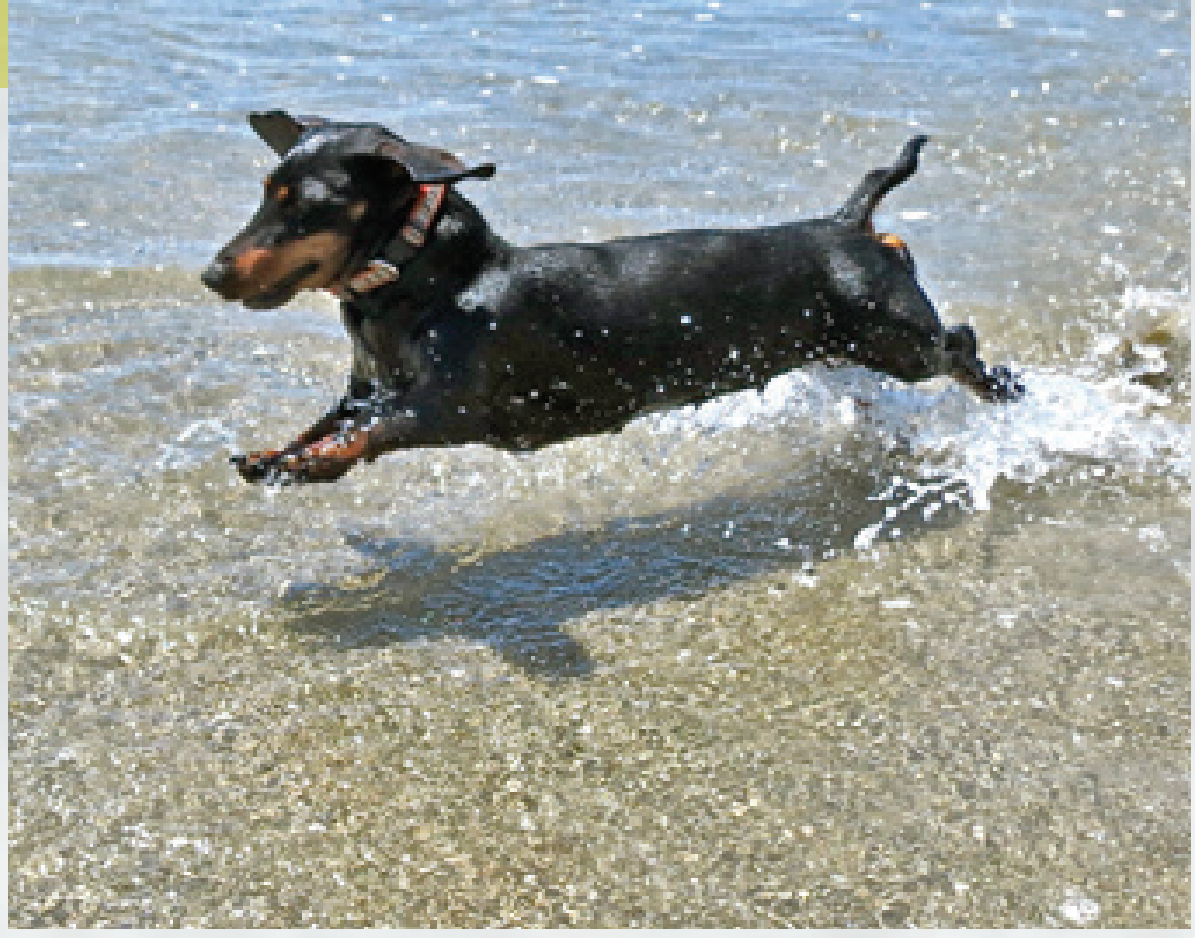

